\title{
STRAINS OF STRAWBERRY CLOVER
}

By L. W. GORMAN, Senior Ecologist, Grasslands Division, Department of Scientific and Industrial Research, Palmerston North.

Strawberry clover when growing vigorously is difficult to distinguish from white clover. Its stoloniferous growth and creeping habit resemble that of white clover, the leaf colour is similar, but the distinguishing features are the longer and narrower leaflet of the strawberry clover with the veins of each leaflet very much branched and more closely spaced than in white clover. The flower heads differ also. The flower heads of white clover are usually white, but some may have a pinkish tinge. Strawberry clover flowers are slightly pointed and mostly pinkish to white, closely resembling a ripening strawberry; hence the name strawberry clover. As the flowers ripen the florets of white clover turn down toward the ground, whereas in strawberry clover the whole flower head develops a characteristic "bladdery" appearance with further resemblances to the' fruit of the common strawberry plant. Strawberry clover seed is larger than that of white clover, but slightly smaller than that of red clover. The seed colour. may vary, but is principally reddish brown or yellow, distinctly flecked, with dark markings.

As a plant strawberry clover can stand wide extremes of temperature. It develops a strong fibrous root system and can withstand both drier and wetter conditions than white clover can,. It is of particular value on wet soils both saline and alkaline. Its particular feature is that 'the plants can be submerged for months under water with a high salt concentration, and yet as soon as the' surplus water drains. away or the water-table falls below ground level fresh growth-begins-and-the-plants-grow vigorously.

Strawberry clover is found growing in various localities in both islands; but mainly in low-lying areas near the sea coast.

For the purpose of the trials described in this 
paper seed samples were collected from as many different sources as possible. A limited number came from commercial samples, a number were hand collected from places where strawberry. clover was prominent in the sward, and some were obtained from overseas. To these were added collections of plants. In all there were 52 samples made up as follows:

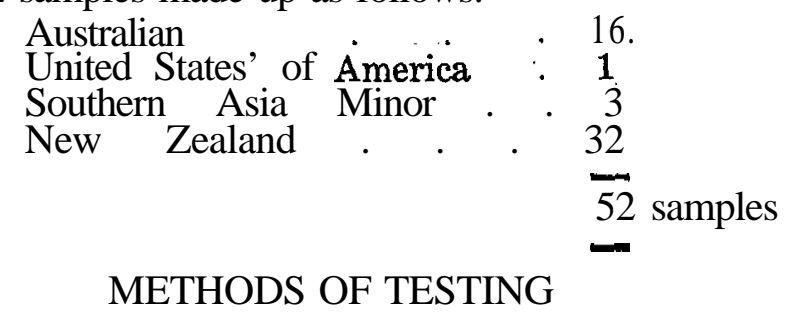

From previous experience we found that it was difficult under field conditions to keep volunteer white dover out of plantings of strawberry clover 'during the establishment stages; so this time seedlings and cuttings from collected plants were grown in boxes of sterilised soil and then planted out as clumps which quickly spread out and occupied $3 \mathrm{ft}$. in each direction. Observations on relative growth were recorded and some measurements of yield of herbage were obtained.

Most strains, of strawberry clover make growth in spring, summer, and autumn, especially in summer, and become relatively dormant in winter. The outstanding 'exception to the above is- one strain which is known as Palestine on account of its origin, the Jordan Valley.' This is a large-leaved, vigorous type which grows "rapidly throughout the year, particularly in winter and early spring.

After the performance of the collection of strains in our trials had been studied and measured it was possible to define 3 distinct classes. follows:-

Group 1-Plants with large leaves, long petioles, vigorous growth, -erect, tall, and spreading, strongly developed stolons, excellent growth, particularly in winter,. good flowering, and reasonably good seed settmg.

Group 2-Plants with medium-sized leaves, mediumlength petioles, dense, leafy growth, spreading habit, slender stolons, good growth in most seasons of the year, and average flowering and seed setting. 


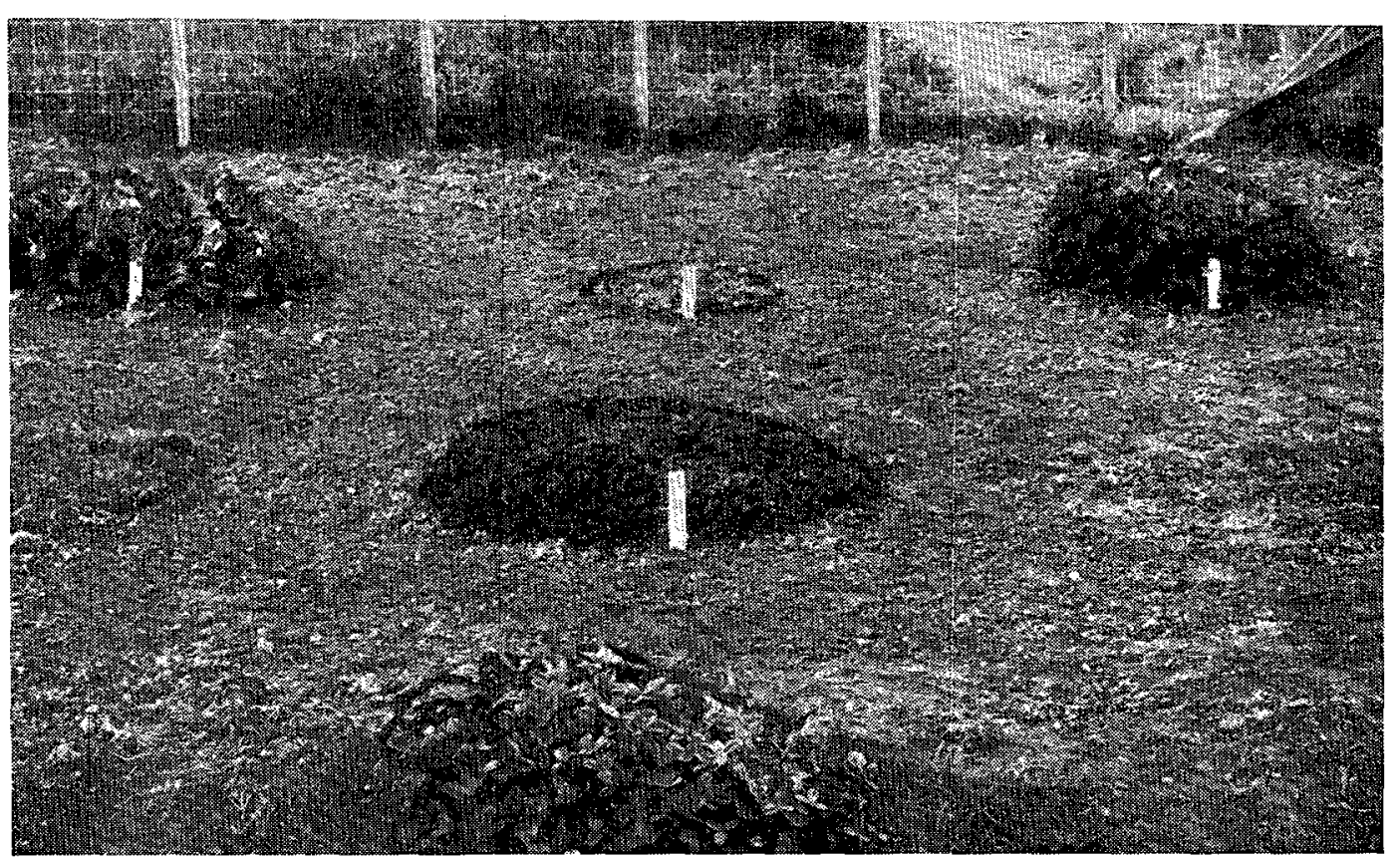

Strains of strawberry clover. Foreground: Palestine group 1 and Australian group V

Background (left to right): Palestine group 1, Commercial group 3, Palestine group 1. 


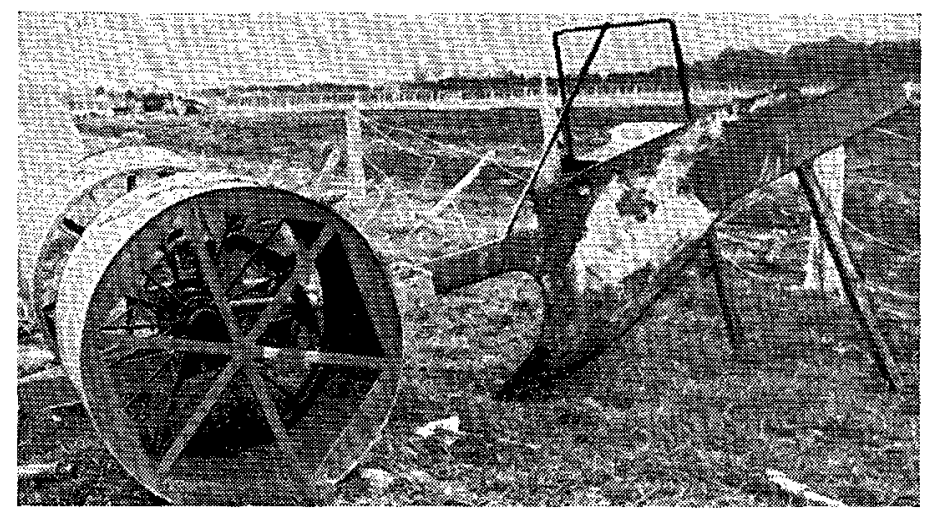

A' Killefer ditch digger which was used satisfactorily for digging the drain shown below.

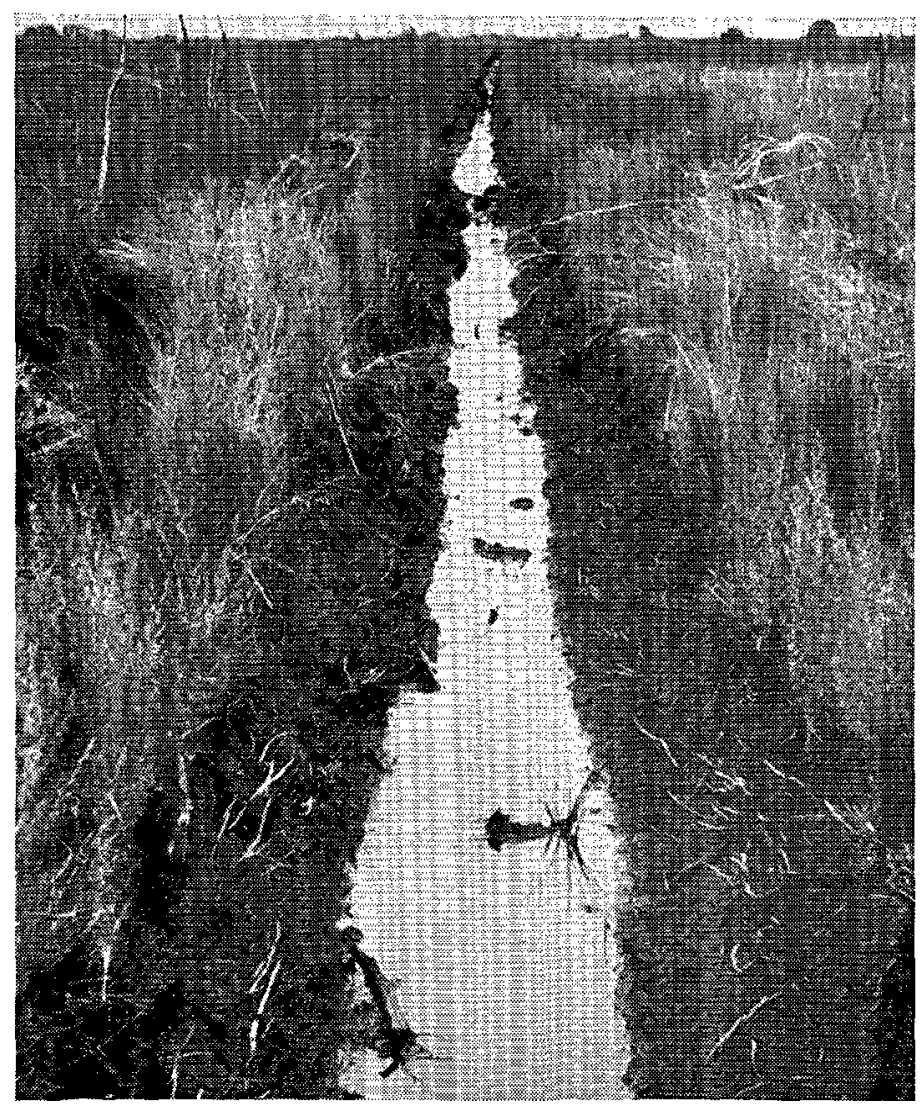

A drain $2 \mathrm{ft}$. wide and $2 \mathrm{ft}$. deep dug by the Killefer ditch digger. 
Group 3-Plants with small leaves, . short petioles, inferior growth, slowly spreading, relatively free seeding, and extremely winter dormant.

With this classification there. were 8 samples in the first group, 28 in the second, and 16 in the third group.

Each of the samples in Group 1 was of Australian origin and 6 out of the 8 were selections or harvestings of the Palestine strain.

Most of the samples in Group 2 were plants collected from places where. strawberry clover is already well established. The majority were New Zealand samples collected in Hawkes Bay and Poverty Bay. Six were from districts in Australia where this clover is being grown successfully. One Australian and one New Zealand sample were outstandingly good, the majority were reasonably good, but some were below average in performance.

It is significant that 8 of the 16 samples in Group 3 were commercially harvested lines and the inferiority of this group as a whole was most striking at all stages of growth. The remaining 8 samples consisted of 2 of Asian origin, 1 from the Yakima Valley in U.S.A., and, the remainder were New Zealand collections.

The relative differences between groups was of the following magnitude:-

Relative leaf growth over

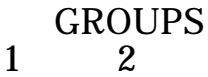

summer ("Palestine"=100) 10027

Relative--dry-matter-yields

late autumn-early winter

("Palestine" $=100$ )

$100 \quad 47 \quad$ Negligible

In an endeavour to establish the. real value of these types under field conditions tillers. from plants representative of the above groups were planted out in a suitable block. at Himatangi 3 years ago. Establishment has been slow, but the dry matter yields -of strawberry clover dissected out of the herbage cut from squares. in May of this year were in the relative order of Palestine $=100$; Type $2=42$; and the

Commercial-Type $3=-3-1$ -

Each of the above mentioned trials has demonstrated the excellence of the Palestine strain and the inferiority of the usual commercial' strains. Within the second group there were dense, leafy plants which 
might be superior under close grazing management or which could be used to build up .a useful selection. Several of the Australian samples appeared superior to any we have in New Zealand.

\section{S E E D P R O D U C T I O N}

'There are no statistics available to show the acreages harvested, but in general it may be said that supplies of New Zealand grown seed are very limited. Only small acreages are harvested. The most regular harvestings are from round Lake Ellesmere and from a small area in Central Otago. Occasional crops have been taken from coastal areas in Hawkes Bay, between Hastings and Napier, and near Gisborne. For the buyer the price is high and seed frequently is unobtainable. Added to this is the fact that much of the commercial seed in New Zealand is of an inferior type.

In South Australia there has been recognised the scope for a wider use of strawberry clover on neutral to alkaline soils of heavy texture, either under irrigation or where the supply of soil moisture is liberal in early summer. The Palestine strain has proved extremely valuable there, and since its introduction to South Australia in 1930 it has been well tested, 'and from originally hand-planted nucleus areas good sup plies of seed have been built up. A recent communication from South Australia stated: "The Palestine strain is proving an extremely valuable perennial legume for a wide range of soils in our higher rainfall areas. As it is capable of withstanding greater extremes of winter floo'ding and summer drought than white clover, it has largely replaced the latter in many areas of this State."

The South Australian Department of Agriculture has now introduced a seed certification scheme to cover 2 strains of strawberry, clover, namely, Palestine Strain and O'Connor's Strain. The Palestine is the large-leaved type and the O'Connor's is a 'mediumsized, leafy type. There are 2 classes for each 'strain -"Mother seed" and "Standard". The Mother seed has to be of 100 per cent. purity and the Standard seed a purity of 95 per cent. or more.

In the 1952-53 season 50 tons of Palestine seed and 20 tons of $O^{\prime}$ Connors strain were certified; As a result of this and improved harvesting methods, the retail Price of Palestine strawberry clover has been reduced to a more reasonable -figure. 


\section{UTILISATION OF STRAWBERRY CLOVER}

If seed of a superior strain were available at a reasonable price, and could be obtained when required, more strawberry clover would be sown; At present neither of these requirements is. met satisfactorily. It is possible that in future we may be able to obtain supplies of the South Australian certified Palestine strain at a competitive price, but I think we should study the leafy, spreading types and build up a good selection of that type, because for New Zealand requirements it may combine better with our pasture species and stand more severe grazing. For such a selection there is limited material. in New Zealand, but some of the superior types from Victoria and South Australia would be useful additions.

Seed production at present may be regarded as a barrier to progress, but difficulties here are not insuperable. It is possible that under controlled irrigation as practised in Mid-Canterbury highly successful seed crops could be obtained. At present a crop in Central Otago is being grown with the aid of irrigation. Harvesting and threshing are sometimes difficult, but modern machinery can overcome much of this. In Australia it is claimed that higher yields are being obtained by improved harvesting methods.

\section{CONCLUSION}

Strawberry clover is an extremely valuable species for large areas where there is repeated flooding or where poor drainage is a limiting factor in pasture growth. Also it could be most useful in most

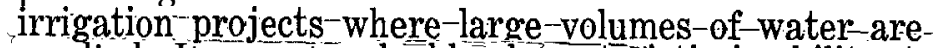
applied, Its most valuable characteristic is ability to survive either continuous flooding or short periods of drought. During the growing seasons its growth is- very good.

The greatest need is to develop a superior strain suitable for our own requirements and to ensure that it gets into commercial seed production.

\section{DISCUSSION}

Q. The speaker is to be congratulated on the advances he has made in trying to produce a strawberry clover suitable for the more fertile low-lying soils. Has he tried to select a strain suitable for the hard, dry hill country? In the Poverty Bay hill country there are odd plants of strawberry clover growing. If a plant suitable for that country could be produced it would be doing the high country man a great service. 
A. That is why a more leafy, low-growing type more like our white clover strain was suggested. It could be used more successfully than the ratther extreme Palestine strain. That is why we are keeping an eye on the more leafy, low-growing type.

Q. Could you give an indication of the relative persistence under severe- grazing?. Would you say the Palestine type would go out more quickly?

A. I have a suspicion that the Palestine type might not stand severe grazing. On a small block we are watching to see if the Palestine strain will stay and I have been surprised to find it has held its own.

Q. As a merchant I know there is definitely a strong demand for strawberry clover seed and a shortage of supplies. When we can get the seed it is apparently inferior. Is the Department taking steps to certify strawberry clover seed. even if it entails sending an officer to Australia \&investigate a system of saving seed?

A. In New 'Zealand there is no seed to certify, and perhaps only one or two areas approaching the conditions for certification. We would have to go through what is available and see what could be reproduced. Regrowing would have to be done under very close protection. Strawberry clover being in less demand than white clover, we would come up against difficulties. Perhaps it would need a Government Department growing nucleus seed and then passing it to farmers.

Q. (Corkill): Mr Gorman has alreadv shown strain variations. Shouldn't we select an improved strain and get it certified? Resources and personnel at Grasslands are limited. Is work on breeding a new strain of strawberry clover warranted? We have done some preliminary work as a basis. We find that only about 1 in 8 are self-fertile. Is work on strawberry clover warranted when so many other plants are wanted?

Q. Is there any information on the nitrogen-fixing powers of strawberry clover in relation to other clovers? South Australian experience shows that it may out-produce white clover in this.

A. This aspect has not come within the scope of my study of the plant. 